\title{
Contraception
}

Contraception 62 (2000) 253-257

Original research article

\section{Influence of two dietary fibers in the oral bioavailability and other pharmacokinetic parameters of ethinyloestradiol}

\author{
Juan J. García*, Nélida Fernández, M. José Diez, Ana Sahagún, Aránzazu González, \\ M. Luisa Alonso, Carlos Prieto, Angela P. Calle, Matilde Sierra \\ Departamento de Farmacología, Toxicología y Enfermería. Universidad de León, León, Spain
}

Received 10 July 2000; accepted 9 October 2000

\begin{abstract}
Dietary fibers are widely used in hypoglycaemic, hypolipidemic, slimming diets. It is probable that their ingestion coincides with the oral administration of drugs and a modification of their pharmacokinetics can appear. In the present study, the influence of two soluble fibers (guar gum and psyllium) was evaluated on the pharmacokinetics of ethinyloestradiol (EE) when they were administered together to female rabbits via the oral route. Three groups of rabbits were used. All animals received $1 \mathrm{mg} / \mathrm{kg}$ of EE; this compound was administered alone in the control group and with $3.5 \mathrm{~g}$ of guar gum or psyllium in the other two groups. When guar gum was administered, there was a decrease in the extent of EE absorbed, but no change was observed in the rate of absorption. When psyllium was administered, the extent of EE absorbed increased slightly and the rate of absorption was slower. (C) 2001 Elsevier Science Inc. All rights reserved.
\end{abstract}

Keywords: Ethinyloestradiol; Guar gum; Psyllium; Pharmacokinetics; Fiber; Rabbits

\section{Introduction}

Ethinyloestradiol (EE) is widely used for oral contraception by millions of women all over the world. This estrogen is also used in the treatment of menopausal symptoms, in functional uterine bleeding, for inhibition of lactation, and also for palliative treatment of breast cancer in postmenopausal women and prostate cancer $[1,2]$.

EE usually is administered via the oral route and at very low doses (20-35 $\mu \mathrm{g}$ in oral contraception) to avoid its adverse effects. The presence of other drugs and/or foods can modify the bioavailability of EE, increasing or decreasing its plasma concentrations; this may lead, respectively, to adverse effects or to a reduction in therapeutic effectiveness.

Dietary fiber, the digestable cell wall component of plant materials, plays an important role in human health [3]. Burkitt [4] attributed part of the lower risk of colon cancer in Africans to their high unabsorbable-fiber diet. Since that time, high dietary fiber intake has been shown to help prevent or treat hyperlipidemia [5], cardiovascular disease

\footnotetext{
* Corresponding author. Tel.: +34-987-29-15-52; fax: +34-987-2912-52.

E-mail address: dftjgv@unileon.es (J.J. García).
}

[6], hypertension [7], obesity [8], certain cancers [9], gastrointestinal disorders [10], and diabetes [11].

Dietary fiber has received considerable attention in both the popular press and scientific literature, so many people know of its beneficial properties. The recommended intake for a healthy adult is $20-35 \mathrm{~g} /$ day [12] and this quantity is, on many occasions, far from the real consumption. To compensate for deficiency in fiber ingestion, pharmaceutical preparations of fiber are frequently used, usually without medical control, in a continued and sometimes abusive way. It is highly probable that fiber ingestion coincides with oral administration of other drugs, including EE, which is used in chronic therapies. Psyllium and guar gum are among these fiber supplements that have been incorporated into diet because of their laxative and hypoglycaemic characteristics and their common use in weight-loss diets.

In a previous study [13] performed with female rabbits, we showed that the extent of EE absorbed decreased between $29 \%$ and $35 \%$, respectively, when it was administered with two commercial fibers containing $2 \%$ and $76.5 \%$ (Product 1) and $2.2 \%$ and $65 \%$ (Product 2) soluble and insoluble fibers, respectively. No other absorption and elimination parameter was modified except $\mathrm{C}_{\max }$, which was lower in the presence of the two fibers. We therefore, 
concluded that EE adsorption to fiber is the most probable interaction mechanism.

The purpose of this study was to establish the influence of two soluble fibers, psyllium (at 70\%) and guar gum (at $83.3 \%$ ), that provide the aqueous solution a high viscosity, in the bioavailability and other pharmacokinetic parameters of EE, when administered to female rabbits by the oral route. We also evaluated whether the behavior of these fibers differs from fibers used in the above mentioned study, which contained mainly insoluble components.

\section{Materials and methods}

\subsection{Study design}

Eighteen healthy female New Zealand white rabbits with a body weight range of $2.7-3.2 \mathrm{~kg}$ were used. The environmental conditions were: constant humidity $(55 \pm 10 \%)$, temperature $\left(19 \pm 2^{\circ} \mathrm{C}\right)$ and 12 -h light-12-h dark cycle. The animals were housed in individual metal cages, which allowed the isolation of feces in a lower container to avoid coprophagia. Rabbits were maintained under these conditions at least 1 week before the study, with free access to water and standard laboratory chow. Twenty-four hours before drug administration, the rabbits fasted but had free access to water.

The rabbits were randomly divided into three groups of six animals each. The rabbits in the first group were used as controls and received $1 \mathrm{mg} / \mathrm{kg}$ EE (Sigma ${ }^{\circledR}$, St. Louis, MO, USA). Animals in the second and third groups also received $1 \mathrm{mg} / \mathrm{kg}$ EE and in addition, immediately before EE administration they received $3.5 \mathrm{~g}$ of psyllium (seed cuticles of Plantago ovata, ispaghula husk) and guar gum (Plantaben ${ }^{\circledR}$ and Plantaguar ${ }^{\circledR}$, respectively, Madaus, S.A., Barcelona, Spain), respectively. The estrogen [dissolved in a mixture of water and ethanol $(4: 1 \mathrm{v} / \mathrm{v})]$ and the two fibers dispersed in water were administered by gastric intubation. A total of 50 $\mathrm{mL}$ water was used for fiber administration and cannula cleaning.

Blood samples were obtained from the left carotid artery previously cannulated with a silicone catheter [Silastic ${ }^{\circledR}$ Medical-grade tubing, $1.02 \mathrm{~mm}$ (inner diameter) $\times 2.16$ $\mathrm{mm}$ (outer diameter)]. The catheters were placed under anaesthesia with sodium pentabarbital (Barcia, Madrid, Spain), $30 \mathrm{mg} / \mathrm{kg}$ intravenously.

Blood samples $(3 \mathrm{~mL})$ were collected through the cannula into heparinized containers before, and at 5, 10, 20, 30, 60, 90, 120, 150, 180, and 240 min after EE administration. Plasma was obtained by centrifugation and stored at $-20^{\circ} \mathrm{C}$ until analyzed. EE was quantified in the plasma samples by high-performance liquid chromatography with electrochemical detection according to the method previously described [14].

\subsection{Pharmacokinetic studies}

\subsubsection{Compartmental analysis}

For compartmental analysis, plasma EE concentrationtime profiles were individually fitted to the following exponential equation:

$$
\mathrm{C}_{\mathrm{p}}=\sum_{\mathrm{i}=1}^{\mathrm{n}} \mathrm{C}_{\mathrm{i}} \mathrm{e}^{-\lambda, \mathrm{t}}
$$

where $C_{i}$ is the y-intercept, $\lambda$ is the slope of each of $n$ first-order rate processes, $\mathrm{e}$ is the exponential function (base $\mathrm{e})$, and $\mathrm{t}$ is time.

The pharmacokinetic model best describing the plasma concentration-time curves of EE was determined using the PCNONLIN computer program (Statistical Consultants, Lexington, KY, USA) [15]. The equations were fitted to the data using a weighting factor $(1 / C)$, and the optimum number of first-order rate processes was determined by residual analysis. Other compartmental parameters were calculated by standard methods [16]. Initial estimates of the parameters were determined by JANA [17].

\subsubsection{Non-compartmental analysis}

Expressions based on statistical moments theory [18] and on formulae described by Gibaldi and Perrier [16] were used to calculate the model-independent pharmacokinetic parameters. The plasma elimination rate constant $(\lambda)$ was calculated by least-squares regression of the logarithm of plasma concentration versus time curve over the terminal elimination phase.

Other parameters calculated were the area under plasma concentration-time from time 0 to the last experimental time $\left(\mathrm{AUC}_{0-\mathrm{t}}\right)$, the area under the plasma concentration-time from time 0 to infinity $\left(\mathrm{AUC}_{0-\infty}\right)$, the total body clearance $(\mathrm{Cl})$, and the half-life associated with $\lambda$ phase $\left(\mathrm{t}_{1 / 2 \lambda}\right)$. Maximum plasma EE concentration $\left(\mathrm{C}_{\max }\right)$ and the time to reach maximum concentration $\left(t_{\max }\right)$ were read directly from the individual plasma concentration-time curves.

\subsection{Statistical analysis}

All pharmacokinetic parameters were calculated for each animal and the data presented as arithmetic mean \pm standard deviation (mean $\pm \mathrm{SD}$ ). Data were analysed by analysis of variance (ANOVA) and when the results were significant, the Duncan's test was used to evaluate differences between data sets. When the data were not normal or there was not uniformity in the variance, Kruskal-Wallis test was used. $\mathrm{P} \leq 0.05$ was used as the level of significance for all analyses.

\section{Results}

The plot of mean plasma EE concentration as a function of time after oral administration of $1 \mathrm{mg} / \mathrm{kg}$ for the three groups 


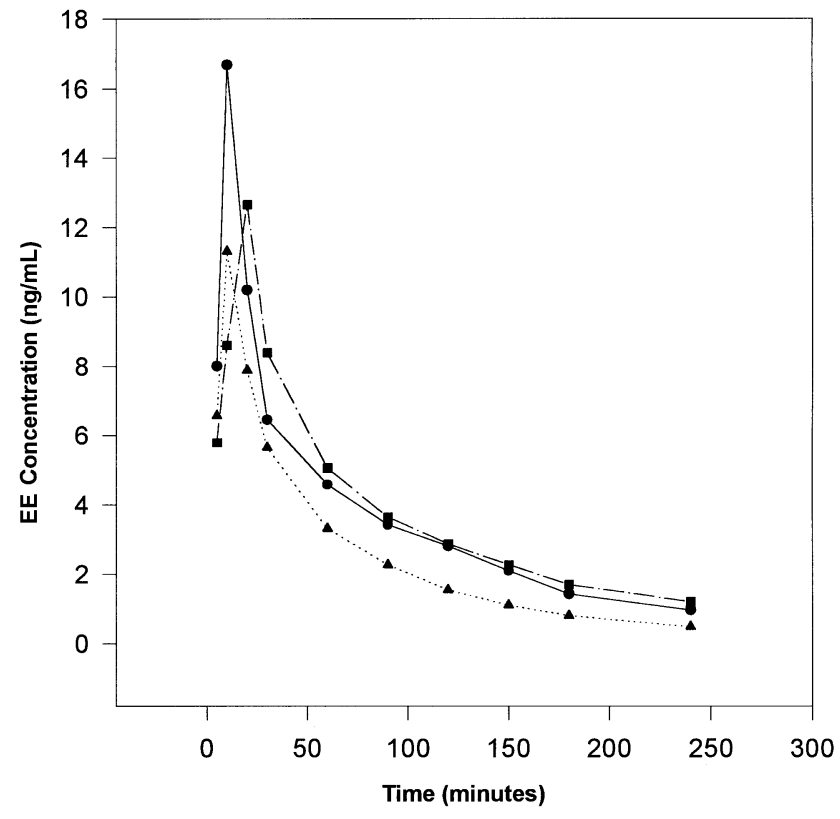

Fig. 1. Mean plasma concentrations of ethinylestradiol (EE) in rabbits after oral administration of $1 \mathrm{mg} / \mathrm{kg}$ alone (- - ) and in the presence of guar gum ( $-\mathbf{\Delta}-)$ and psyllium ( $-\mathbf{\square}-)$.

studied are shown in Fig. 1. The pharmacokinetic parameters obtained by both compartmental and non-compartmental analyses are summarized in Tables 1 and 2, respectively.

\subsection{Compartmental analysis}

After oral administration (with and without fiber), the pharmacokinetics of EE was best described by a two-com- partment open model in all rabbits. The mean values obtained for $\mathrm{k}_{\mathrm{a}}$ were very similar in the control $\left(0.130 \mathrm{~min}^{-1}\right)$ and guar gum $\left(0.132 \mathrm{~min}^{-1}\right)$ groups, and was lower in the psyllium group $\left(0.083 \mathrm{~min}^{-1}\right)$. Significant differences were found when this parameter was compared between the psyllium group, and the control and guar gum groups.

The mean AUC value was 1.5 times higher in the control group $\left(975 \mathrm{ng} \cdot \mathrm{min} \cdot \mathrm{mL}^{-1}\right)$ than in the guar gum group $\left(652 \mathrm{ng} \cdot \min \cdot \mathrm{mL}^{-1}\right)$, and slightly lower than in psyllium group $\left(1102 \mathrm{ng} \cdot \mathrm{min} \cdot \mathrm{mL}^{-1}\right)$.

$\mathrm{C}_{\max }$ values were higher in the control group (12.5 $\left.\mathrm{ng} \cdot \mathrm{mL}^{-1}\right)$ than in guar gum $\left(9.5 \mathrm{ng} \cdot \mathrm{mL}^{-1}\right)$ and psyllium $\left(10.4 \mathrm{ng} \cdot \mathrm{mL}^{-1}\right)$ groups, and $\mathrm{t}_{\max }$ values were lower in the control group (10.6 min) than in the guar gum (11.2 min) and psyllium (17.8 min) groups.

According to Ritchel [19] and McGilveray et al. [20], the most representative parameters of bioavailability are AUC, $\mathrm{C}_{\max }$, and $\mathrm{t}_{\max }$. The statistical analysis for these parameters revealed that there were significant differences when AUC was compared between the guar gum group, and the control and psyllium groups. Significant differences were also found for $t_{\max }$. However, no significant differences were found when $\mathrm{C}_{\max }$ values were compared.

$\beta$ values ranged from $0.0091 \mathrm{~min}^{-1}$ and $0.0080 \mathrm{~min}^{-1}$ (guar gum and control group, respectively) to $0.0065 \mathrm{~min}^{-1}$ (psyllium group). Statistical analysis revealed no significant differences for $\beta$ values.

Finally, significant differences were found for $\mathrm{Cl}$ between the guar gum group $\left(1.647 \mathrm{~L} \cdot \mathrm{kg}^{-1} \cdot \mathrm{min}^{-1}\right)$ and control $\left(1.072 \mathrm{~L} \cdot \mathrm{kg}^{-1} \cdot \mathrm{min}^{-1}\right)$ and psyllium $(0.973$ $\left.\mathrm{L} \cdot \mathrm{kg}^{-1} \cdot \mathrm{min}^{-1}\right)$ groups.

Table 1

Pharmacokinetic parameters obtained by compartmental analysis in rabbits after oral administration of $1 \mathrm{mg} / \mathrm{kg}$ EE alone (control) and in the presence of fiber (guar gum or Ispaghula husk) ${ }^{\mathrm{a}}$

\begin{tabular}{lccr}
\hline Parameters & Control & Guar gum & Psyllium \\
\hline $\mathrm{A}\left(\mathrm{ng} \cdot \mathrm{mL}^{-1}\right)^{\mathrm{b}}$ & $98.3 \pm 2.42$ & $80.4 \pm 30.1$ & $87.6 \pm 13.1$ \\
$\mathrm{~B}\left(\mathrm{ng} \cdot \mathrm{mL}^{-1}\right)^{\mathrm{c}}$ & $6.39 \pm 1.01$ & $4.27 \pm 2.02$ & $5.74 \pm 2.06$ \\
$\mathrm{~K}_{\mathrm{a}}\left(\mathrm{min}^{-1}\right)^{\mathrm{d}, \mathrm{g}, \mathrm{h}}$ & $0.130 \pm 0.009$ & $0.132 \pm 0.025$ & $0.083 \pm 0.027$ \\
$\alpha\left(\mathrm{min}^{-1}\right)^{\mathrm{c}}$ & $0.1032 \pm 0.0114$ & $0.0998 \pm 0.0433$ & $0.0680 \pm 0.0257$ \\
$\beta\left(\mathrm{min}^{-1}\right)^{\mathrm{c}}$ & $0.0080 \pm 0.0014$ & $0.0091 \pm 0.0020$ & $0.0065 \pm 0.0018$ \\
$\mathrm{~K}_{10}\left(\mathrm{~min}^{-1}\right)^{\mathrm{d}, \mathrm{g}, \mathrm{h}}$ & $0.0274 \pm 0.0034$ & $0.0303 \pm 0.0079$ & $0.0205 \pm 0.0044$ \\
$\mathrm{~K}_{12}\left(\mathrm{~min}^{-1}\right)^{\mathrm{b}}$ & $0.0538 \pm 0.0093$ & $0.0478 \pm 0.0293$ & $0.0313 \pm 0.0162$ \\
$\mathrm{~K}_{21}\left(\mathrm{~min}^{-1}\right)^{\mathrm{c}}$ & $0.0299 \pm 0.0047$ & $0.0308 \pm 0.0153$ & $0.0228 \pm 0.0119$ \\
$\mathrm{AUC}\left(\mathrm{ng} \cdot \min \cdot \mathrm{mL}^{-1}\right)^{\mathrm{d}, \mathrm{f}, \mathrm{h}}$ & $975 \pm 205$ & $652 \pm 193$ & $1102 \pm 307$ \\
$\mathrm{Cl}(\mathrm{L} \cdot \mathrm{kg}$ & $1.65 \pm 0.48$ & $0.97 \pm 0.29$ \\
$\mathrm{t}_{1 / 2 \mathrm{~K} 10}(\mathrm{~min})^{\mathrm{d}, \mathrm{g}, \mathrm{h}}$ & $1.07 \pm 0.27$ & $24.2 \pm 5.90$ & $35.3 \pm 8.16$ \\
$\mathrm{t}_{1 / 2 \mathrm{Ka}}(\mathrm{min})^{\mathrm{e}}$ & $25.7 \pm 3.13$ & $5.38 \pm 0.89$ & $9.07 \pm 2.74$ \\
$\mathrm{t}_{1 / 2 \alpha}(\mathrm{min})^{\mathrm{b}}$ & $5.36 \pm 0.36$ & $9.16 \pm 6.87$ & $11.4 \pm 3.97$ \\
$\mathrm{t}_{1 / 2 \beta}(\mathrm{min})^{\mathrm{d}, \mathrm{h}}$ & $6.79 \pm 0.78$ & $79.2 \pm 15.2$ & $112 \pm 25.9$ \\
$\mathrm{~V}_{\mathrm{c}}(\mathrm{L} \cdot \mathrm{kg}$ & \\
$\mathrm{C}_{\max }\left(\mathrm{ng} \cdot \mathrm{mL}^{-1}\right)^{\mathrm{b}}$ & $89.5 \pm 17.6$ & $0.0565 \pm 0.0183$ & $0.0486 \pm 0.0159$ \\
$\mathrm{t}_{\max }(\mathrm{min})^{\mathrm{e}}$ & $0.0392 \pm 0.0083$ & $9.52 \pm 3.03$ & $10.4 \pm 2.52$ \\
\hline
\end{tabular}

${ }^{a}$ Values are the mean \pm standard deviation for six rabbits.

${ }^{\mathrm{b}}$ No significant differences (Kruskal-Wallis).

${ }^{\mathrm{c}}$ No significant differences (one-way ANOVA).

Significant differences ( ${ }^{\mathrm{d}}$ Duncan test) $\left({ }^{\mathrm{e}}\right.$ Kruskal-Wallis) between: ${ }^{\mathrm{f}}$ control and guar gum, ${ }^{\mathrm{g}}$ control and psyllium, ${ }^{\mathrm{h}}$ guar gum and psyllium. 
Table 2

Pharmacokinetic parameters obtained by non-compartmental analysis in rabbits after oral administration of $1 \mathrm{mg} / \mathrm{kg}$ EE alone (control) and in the presence of fiber (guar gum or Ispaghula husk) ${ }^{\mathrm{a}}$

\begin{tabular}{lccc}
\hline Parameters & Control & Guar gum & Ispaghula husk \\
\hline$\lambda\left(\mathrm{min}^{-1}\right)^{\mathrm{b}}$ & $0.0070 \pm 0.0022$ & $0.0097 \pm 0.0023$ & $0.0071 \pm 0.0015$ \\
$\mathrm{AUC}$ & $607 \pm 179$ & $916 \pm 243$ \\
$\mathrm{AUC} \mathrm{t}_{-\infty}\left(\mathrm{ng} \cdot \mathrm{min} \cdot \mathrm{min} \cdot \mathrm{mL}^{-1}\right)^{\mathrm{c}, \mathrm{e}, \mathrm{g}}$ & $876 \pm 166$ & $52.1 \pm 28.6$ & $186 \pm 105$ \\
$\mathrm{AUC})_{0-\infty}^{\mathrm{d}}\left(\mathrm{ng} \cdot \mathrm{min} \cdot \mathrm{mL}^{-1}\right)^{\mathrm{c}, \mathrm{e}, \mathrm{g}}$ & $146 \pm 45.8$ & $659 \pm 198$ & $1101 \pm 316$ \\
$\mathrm{Cl}\left(\mathrm{L} \cdot \mathrm{kg}^{-1} \cdot \mathrm{min}^{-1}\right)^{\mathrm{e}, \mathrm{f}, \mathrm{h}}$ & $1022 \pm 168.6$ & $1.634 \pm 0.474$ & $171 \pm 40.7$ \\
$\mathrm{~V}_{\mathrm{a}}\left(\mathrm{L} \cdot \mathrm{kg}^{-1}\right)^{\mathrm{b}}$ & $1.006 \pm 0.203$ & $74.8 \pm 16.7$ & $139 \pm 39.2$ \\
$\mathrm{t}_{1 / 2 \lambda}\left(\mathrm{min}^{-1}\right)^{\mathrm{b}}$ & $160 \pm 67.4$ & $11.3 \pm 2.98$ & $102 \pm 28.3$ \\
$\mathrm{C}_{\max }\left(\mathrm{ng} \cdot \mathrm{mL}^{-1}\right)^{\mathrm{c}, \mathrm{e}}$ & $108 \pm 31.3$ & 10.0 & $13.0 \pm 4.37$ \\
$\mathrm{t}_{\max }(\mathrm{min})^{\mathrm{d}, \mathrm{f}, \mathrm{g}}$ & $16.7 \pm 2.01$ & 10.0 & $18.3 \pm 4.08$
\end{tabular}

${ }^{a}$ Values are the mean \pm standard deviation for six rabbits.

${ }^{\mathrm{b}}$ No significant differences (one-way ANOVA).

Significant differences ( ${ }^{\mathrm{C}}$ Duncan test) $\left({ }^{\mathrm{d}}\right.$ Kruskal-Wallis) between: ${ }^{\mathrm{e}}$ control and guar gum, ${ }^{\mathrm{f}}$ control and psyllium, ${ }^{\mathrm{g}}$ guar gum and psyllium.

\subsection{Non-compartmental analysis}

Non-compartmental AUC values were also higher in the control group $\left(1022 \mathrm{ng} \cdot \mathrm{min} \cdot \mathrm{mL}^{-1}\right)$ than in guar gum group $\left(659 \mathrm{ng} \cdot \mathrm{min} \cdot \mathrm{mL}^{-1}\right)$, and slightly lower than in psyllium group $\left(1101 \mathrm{ng} \cdot \mathrm{min} \cdot \mathrm{mL}^{-1}\right)$. Significant differences were found for this parameter between the guar gum group and the other two groups. $\mathrm{C}_{\max }$ obtained in the control group $\left(16.7 \mathrm{ng} \cdot \mathrm{mL}^{-1}\right)$ was higher than in psyllium group $\left(13.0 \mathrm{ng} \cdot \mathrm{mL}^{-1}\right)$ and guar gum group $\left(11.3 \mathrm{ng} \cdot \mathrm{mL}^{-1}\right)$. Statistical analysis revealed significant differences between the control group and guar gum group. The mean value of $\mathrm{t}_{\max }$ was $10 \mathrm{~min}$ in the control and guar gum groups, while in the psyllium group $t_{\max }$ was 18.3 min. The differences were significant between the latter group and the former two. Lambda values were similar to $\beta$ values obtained after compartmental analysis.

Finally, significant differences were found for $\mathrm{Cl}$ between the guar gum group $\left(1.634 \mathrm{~L} \cdot \mathrm{kg}^{-1} \cdot \mathrm{min}^{-1}\right)$, and control $\left(1.006 \mathrm{~L} \cdot \mathrm{kg}^{-1} \cdot \mathrm{min}^{-1}\right)$ and psyllium $\left(0.975 \mathrm{~L} \cdot \mathrm{kg}^{-1} \cdot \mathrm{min}^{-1}\right)$ groups.

\section{Discussion}

The two-compartment open model was used by other authors to describe EE pharmacokinetics [21-24]. This model has also been used to describe the results obtained in this study as well as in 3 previous studies where the oestrogen was administered orally and intravenously $[13,25$, 26].

The mean value obtained for $\mathrm{C}_{\max }$ in the control group $\left(12.5 \pm 2.7 \mathrm{ng} \cdot \mathrm{mL}^{-1}\right)$ was slightly lower than obtained in a previous study $\left(14.5 \pm 3.2 \mathrm{ng} \cdot \mathrm{mL}^{-1}\right)$, while the AUC value was higher (629 and $975 \mathrm{ng} \cdot \mathrm{mL}^{-1}$, respectively). We think that these differences are due to individual variability. The value of $\mathrm{t}_{\max }$, however, was very similar in both studies: $9.5 \pm 1.2 \mathrm{~min}$ in the previous study and $10.6 \pm 0.8 \mathrm{~min}$ in the present work.
Although there are many studies regarding pharmacokinetic interactions, few of them have been carried out with dietary fiber. Dietary fibers have important effects in gastrointestinal physiology and in absorption of many nutrients. Fiber is also considered to be capable of binding toxic materials and eliminating them before they can be absorbed into the blood stream [27]. In the same way, it can modify drug absorption.

In a previous study we showed that two fibers containing a high proportion of insoluble components (fiber 1 contained a $76.5 \%$ of wheat bran and fiber 2 contained $65 \%$ Plantago ovata seeds) reduced the extent of EE absorbed, without modifying the rate of absorption $\left(t_{\max }\right.$ and $K_{a}$ values were similar to those obtained in the control group). The values of AUC and $\mathrm{C}_{\max }$ decreased between $29 \%$ and $35 \%$.

In this study, two hydrosoluble fibers with widespread usage among consumers were studied: guar gum and psyllium, which provide the aqueous medium with high viscosity. Under these conditions, the extent of EE absorbed could be even lower than in the presence of insoluble fibers. In the presence of guar gum, AUC decreased by $35.6 \%$ and $\mathrm{C}_{\max }$ by $32.2 \%$. These values are similar to those obtained for fibers 1 and 2, which reduced the extent of EE absorbed between $29 \%$ and $35 \%$. As we concluded with wheat bran and Plantago ovata seeds, we think that in the present study guar gum acts as a mechanical barrier that prevents EE access to mucosal surfaces, resulting in decreased drug absorption and a shortened duration of action. These facts are in accordance with Kirk [28], who indicated that there is a type of drug-nutrient interaction involving food as a mechanical barrier that prevents drug access to mucosal surfaces.

However, in the presence of psyllium, the behavior is different to that observed with the other three situations. There is a delay in the absorption, as can be deduced from the higher value of $\mathrm{t}_{\max }(17.8 \mathrm{~min})$ and the lower value of $\mathrm{K}_{\mathrm{a}}$ (0.083 $\left.\mathrm{min}^{-1}\right)$ obtained in comparison with the control group (10.6 min and $0.130 \mathrm{~min}^{-1}$ ). On the other hand, the extent absorbed (AUC $=1102 \mathrm{ng} \cdot \mathrm{min} \cdot \mathrm{mL}^{-1}$ ) is slightly 
higher than when $\mathrm{EE}$ is administered alone $(\mathrm{AUC}=975$ $\left.\mathrm{ng} \cdot \mathrm{min} \cdot \mathrm{mL}^{-1}\right)$. This fact may indicate a lower absorption in the stomach, where EE is well absorbed [21] and an increase in the absorption in the intestine, where this fiber increases peristaltic movements [29-30].

As indicated by Anderson [31], fiber action is complex and may influence the bioavailability by direct binding of drugs or by altering luminal $\mathrm{pH}$, gastric emptying, intestinal transit, mucosal absorption, splanchnic-hepatic flow and metabolism of the drug. This can be interpreted as a higher or lower absorption and, moreover, it depends not only on the type of fiber but also on the drug. In this way, while in the present study we showed that guar gum diminished EE absorption, Uusitupa et al. [32] did not find any modification in the absorption of glibenclamide when this drug was administered with guar gum.

In relation to the interaction with psyllium, it could be even beneficial, because $\mathrm{C}_{\max }$ would be lower and the risk of adverse reaction would diminish, and as the extent absorbed is not lower, the efficacy would not decrease.

\section{References}

[1] Masterson BJ. Oral contraceptive agents: current status. Am J Surg 1988;155:619-27.

[2] Godsland IF, Cook D, Wynn V. Clinical and metabolic considerations of long-term oral contraceptive use. Am J Obstet Gynecol 1992;166: 1955-63.

[3] Anderson JW. Dietary fiber and human health. Hort Science 1990; 25:1488-95.

[4] Burkitt DP. Related disease-related cause? Lancet 1969;2:1229-31.

[5] Anderson JW, Gustafson NJ. Hypocholesterolemic effects of oat and bean products. Am J Clin Nutr 1988;48:749-53.

[6] Anderson JW, Deakins DA, Floore TL, Smith BM, Whitis SE. Dietary fiber and coronary heart disease. Crit Rev Food Sci Nutr 1990; 29:95-147.

[7] Anderson JW. Plant fiber and blood pressure. Ann Intern Med 1983; 98:843-6.

[8] Anderson JW, Bryant CA. Dietary fiber: diabetes and obesity. Am J Gastroenterol 1986;81:898-906.

[9] Kromhout D, Bosschieter EB, de Lezenne Coulander C. Dietary fiber and 10-year mortality from coronary heart disease, cancer and all causes: the Zutphen Study. Lancet 1982;2:518-22.

[10] Koruda MJ. Dietary fiber and gastrointestinal disease. Surg Gynecol Obstet 1993;177:209-14.

[11] Anderson JW, Akanji AO. Dietary fiber-An overview. Diabetes Care 1991;14:1126-31.

[12] Pilch SM. Physiologic effects and health consequences of dietary fiber. Life Sciences Research Office, Bethesda, MD: Federation of American Societies for Experimental Biology, 1987.
[13] Fernández N, Diez MJ, Terán MT, Garcia JJ, Calle AP, Sierra M. Influence of two commercial fibers in the pharmacokinetics of ethinylestradiol in rabbits. J Pharmacol Exp Ther 1998;286:870-4.

[14] Fernández N, Garcia JJ, Diez MJ, Terán MT, Sierra M. Rapid highperformance liquid chromatographic assay of ethinyloestradiol in rabbit plasma. J Chromatogr Biomed Appl 1993;319:143-7.

[15] Metzler CM, Weiner DL. PCNONLIN user's guide, version 3.0. Lexington, KY: Statistical Consultants, 1989.

[16] Gibaldi M, Perrier D. Multicompartment models. In: Pharmacokinetics. New York: Marcel Dekker, 1982:45-111.

[17] Dunne A. JANA: a new iterative polyexponential curve stripping program. Comput Prog Biomed 1985;20:269-75.

[18] Yamaoka K, Nakagawa T, Uno T. Statistical moments in pharmacokinetics. J Pharmacokinet Biopharm 1978;6:547-58.

[19] Ritchel WA. Methodology of bioavailability assessment. Scienc Techniq Pratiqu Pharmaceut 1987;3:286-301.

[20] McGilveray IJ, Midha KK, Skelly JP, et al. Consensus report from "Bio International '89": issues in the evaluation of bioavailability data. J Pharm Sci 1990;79:945-6.

[21] Goldzieher JW. Pharmacokinetics and metabolism of ethinyl estrogens. In: Goldzieher JW, Fohterby K, editors. Pharmacology of the contraceptive steroids. New York: Raven Press, 1994. p. 127-51.

[22] Fotherby K, Akpoviroro J, Abdel-Rahman HA, et al. Pharmacokinetics of ethinyloestradiol in women from different populations. Contraception 1981;23:487-97.

[23] Back DJ, Breckeridge AM, Cross KJ, Orme ML'E, Thomas E. An antibiotic interaction with ethinyloestradiol in the rat and rabbit. $\mathrm{J}$ Steroid Biochem 1982;16:407-13.

[24] Düsterberg B, Kühne G, Taüber U. Half-lives in plasma and bioavailability of ethinyloestradiol in laboratory animals. Arzneim-Forsch Drug Res 1986;36:1187-90.

[25] Fernández N, Sierra M, Diez MJ, Terán MT, Sahagún AM, García JJ. Pharmacokinetics of ethinyloestradiol in rabbits after intravenous administration. Contraception 1996;53:307-12.

[26] Fernández N, Sierra M, Diez MJ, Terán MT, Pereda P, García JJ. Study of the pharmacokinetic interaction between ethinyloestradiol and amoxicillin in rabbits. Contraception 1997;55:47-52.

[27] Meseguer Soler I, Martínez Para MC, Farré Rovira R. Dietary fiber (I). Definition, properties and composition. Med Clin (Barc) 1997; 16:641-4.

[28] Kirk JK. Significant drug-nutrient interactions. Am Fam Physician 1995;51:1175-82.

[29] Eastwood MA, Morris ER. Physical properties of dietary fiber that influence physiological function: a model for polymers along the gastrointestinal tract. Am J Clin Nutr 1992;55:436-42.

[30] Trowell H, Burkitt D. Physiological role of dietary fiber: a ten-year review. ASDC J Dent Child 1986;53:444-7.

[31] Anderson KE. Influences of diet and nutrition on clinical pharmacokinetics. Clin Pharmacokinet 1988;14:325-46.

[32] Uusitupa M, Sodervik H, Silvasti M, Karttunen P. Effects of a gel forming dietary fiber, guar gum, on the absorption of glibenclamide and serum lipids in patients with non-insulin dependent (type 2) diabetes. Int J Clin Pharmacol Ther Toxicol 1990;28:153-7. 